\title{
Paediatric anti-neutrophil cytoplasmic antibody (ANCA) -associated vasculitis: an update on renal management
}

\author{
Lucy A Plumb ${ }^{1} \cdot$ Louise Oni $^{2}$ (D) Stephen D Marks ${ }^{1} \cdot$ Kjell Tullus $^{1}$
}

Received: 4 September 2016 / Revised: 17 November 2016 / Accepted: 21 November 2016 /Published online: 6 January 2017

(C) The Author(s) 2017. This article is published with open access at Springerlink.com

\begin{abstract}
The anti-neutrophil cytoplasmic antibody (ANCA)associated vasculitides (AAV) are a group of disorders characterized by necrotizing inflammation of the small to medium vessels in association with autoantibodies against the cytoplasmic region of the neutrophil. Included in this definition are granulomatosis with polyangiitis (GPA, formerly known as Wegener's granulomatosis), microscopic polyangiitis (MPA) and eosinophilic granulomatosis with polyangiitis (formerly known as Churg-Strauss syndrome). AAV are chronic, often relapsing diseases that can be organ or life threatening. Despite immunosuppression, the morbidity and mortality remain high. Renal involvement contributes significantly to the morbidity with high numbers of patients progressing to end-stage kidney disease. Current therapies have enabled improvements in renal function in the short term, but evidence for long-term protection is lacking. In MPA, renal involvement is common at presentation (90\%) and often follows a more severe course than that seen in paediatric GPA. Renal biopsy remains the 'gold standard' in diagnosing ANCAassociated glomerulonephritis. While GPA and MPA are considered separate entities, the two are managed identically. Current treatment regimens are extrapolated from adult studies, although it is encouraging to see recruitment of paediatric patients to recent vasculitis trials. Traditionally more severe disease has been managed with the 'gold standard' treatment of glucocorticoids and cyclophosphamide, with remission rates achieved of between 70
\end{abstract}

Louise Oni

louise.oni@liverpool.ac.uk

1 Department of Paediatric Nephrology, Great Ormond Street Hospital for Children NHS Foundation Trust, London, UK

2 Department of Women's and Children's Health, Institute of Translational Medicine, Alder Hey Children's Hospital, Eaton Road, Liverpool L12 2AP, UK and $100 \%$. Other agents employed in remission induction include anti-tumor necrosis factor-alpha therapy and mycophenolate mofetil. Recently, however, increasing consideration is being given to rituximab as a therapy for children in severe or relapsing disease, particularly for those at risk for glucocorticoid or cyclophosphamide toxicity. Removal of circulating ANCA through plasma exchange is a short-term measure reserved for severe or refractory disease. Maintenance therapy usually involves azathioprine. The aim of this article is to provide a comprehensive review of paediatric $\mathrm{AAV}$, with a focus on renal manifestations, and to highlight the recent advances made in therapeutic management.

Key words ANCA vasculitis $\cdot$ Management . Glomerulonephritis $\cdot$ Paediatric $\cdot$ Diagnosis

\section{Introduction}

The anti-neutrophil cytoplasmic antibody (ANCA)-associated vasculitides (AAV) are a group of disorders characterized by necrotizing inflammation of the small to medium vessels in association with autoantibodies against the cytoplasmic region of the neutrophil, namely proteinase 3 (PR3) and myeloperoxidase (MPO). Included in this definition are granulomatosis with polyangiitis (GPA, formerly known as Wegener's granulomatosis), microscopic polyangiitis (MPA) and eosinophilic granulomatosis with polyangiitis (EGPA; formerly known as Churg-Strauss syndrome). AAV is a chronic, often relapsing disease that can be organ or life threatening $[1,2]$. While modern immunosuppressive regimens have dramatically improved the prognosis for AAV, the associated disease and therapy-related morbidity and mortality remain high [3]. Renal involvement contributes significantly to the morbidity seen in paediatric $\mathrm{AAV}$, with high numbers of 
patients progressing to end-stage kidney disease (ESKD). Current therapies have enabled improvements in renal function in the short term, but evidence for long-term protection is currently lacking. The disease burden associated with AAV is particularly important in children as they acquire educational achievements and strive to attain satisfactory growth, development and fertility, with the additional burden that they are likely to live with the disease and associated therapies for longer than their adult counterparts. The aim of this article is to provide a comprehensive review of paediatric $\mathrm{AAV}$ with a focus on its renal manifestations, as well as to highlight the recent advances made in therapeutic management.

\section{Diagnosis and classification}

In 2005, the vasculitis working group of the Paediatric Rheumatology European Society (PRES), supported by the European League Against Rheumatism (EULAR) proposed new paediatric-specific classification criteria for GPA [4], which were validated in 2008 [5]. Major differences between EULAR/Paediatric Rheumatology INternational Trials Organisation (PRINTO)/PRES paediatric and the 1990 American College of Rheumatology (ACR) criteria were the addition of computed tomography imaging for pulmonary complications and more specific features for respiratory involvement [5]. The criteria were unable to differentiate MPA and EGPA from GPA due to the rarity of these subtypes, and as such no formal criteria for children are available. Current recommendations from the European Medicines Agency (EMA) to differentiate MPA from GPA are therefore based on an algorithm by Watts et al. [6], which has been validated in paediatric GPA and MPA cases [7].

In 2012, the nomenclature was updated: Wegener's granulomatosis was renamed granulomatosis with polyangiitis, and Churg-Strauss syndrome became eosinophilic granulomatosis with polyangiitis [8]. Given the lack of validated criteria for AAV, the ACR criteria and Chapel Hill Consensus Conference definitions are used as such [9].

\section{Epidemiology}

Although increasingly recognized, AAV remain rare. Due to changes in classification criteria, the true incidence is unclear. Primary systemic vasculitis (PSV) in UK children has an incidence of 10.6 cases per 100,000 population [10]. AAV are very rare; the estimated incidence of GPA in Europe is less than 1 per 2 million population per year [11], with a Canadian study suggesting a higher incidence at 6.39 per million population [12]. The incidence of MPA and EGPA in children is unknown [3] (Table 1).
In adult-onset GPA, males are slightly more at risk than females [13]. The converse is seen in childhood disease, where GPA has a female predominance and tends to present around adolescence $[1,20]$. Childhood MPA also peaks in early adolescence (12 years, range $7-17$ years) $[14,15]$. The geographical distribution of GPA has been shown to increase with increasing latitude, in both northern and southern hemispheres [16]. Ethnicity has also been associated with an increased risk: in a multi-ethnic population from France, GPA, MPA and EGPA were twofold more prevalent in subjects of European descent than in non-Europeans [17].

\section{Aetiology and pathogenesis}

While several hypotheses have been posed, the exact pathogenesis of AAV remains unclear. Both PR3-ANCA and MPOANCA are strongly associated with AAV although they may correlate with separate phenotypes: PR3-ANCA is associated with a granulomatous vasculitis whereas MPO-ANCA correlates with a necrotizing small-vessel vasculitis. Granulomata are not a feature of MPO-ANCA-associated vasculitis. There is increasing evidence that ANCA may play a primary role in the development of necrotizing small-vessel vasculitis [18]. In vitro studies have demonstrated that ANCA can stimulate neutrophils to produce reactive oxygen species and lytic enzymes [21]. Before this can occur, pro-inflammatory cytokines [tumour necrosis factor-alpha (TNF- $\alpha)$, interleukin (IL) 1 and IL 18] must prime the neutrophils, leading to the upregulation of neutrophil adhesion molecules (CD11b) and translocation of PR3/MPO antigens to the neutrophil surface membrane. Subsequent interaction between ANCA and the relevant ANCA-antigen activates the neutrophil, causing increased vessel wall adherence and transmigration. The ensuing ANCA-mediated activation results in neutrophil degranulation and release of reactive oxygen species, resulting in vasculitis [19]. In vivo experimental studies have since confirmed a role for MPO-ANCA in the development of necrotizing vasculitis [18].

Observations that infectious episodes may trigger relapses of AAV have led to the hypothesis that microbial factors may play a role in disease pathogenesis. This possibility is supported by placebo-controlled adult studies that demonstrate a significant reduction in relapses for patients treated with cotrimoxazole [22, 23].

Following reports of familial associations, evidence for genetic susceptibility is increasing. A genome-wide association study performed in $1233 \mathrm{UK}$ patients with AAV and replicated in 1454 Northern European patients has demonstrated genetic associations with AAV and revealed that GPA and MPA are two genetically distinct conditions [24]. The strongest genetic associations were found to correlate with the antigenic specificity of ANCA rather than the clinical phenotype, with anti- 
Table 1 The incidence of anti-neutrophil cytoplasmic antibody-associated vasculitides in adult and childhood populations according to the literature

\begin{tabular}{|c|c|c|c|c|c|c|c|}
\hline \multirow[t]{2}{*}{ Reference } & \multirow[t]{2}{*}{ Country of study } & \multirow[t]{2}{*}{ Study period } & \multirow[t]{2}{*}{ Study population } & \multirow[t]{2}{*}{ Classification criteria } & \multicolumn{3}{|c|}{ Incidence per 100,000 population } \\
\hline & & & & & GPA & MPA & EGPA \\
\hline \multicolumn{8}{|l|}{ Adult cohort data } \\
\hline Watts et al. [12] & UK & 1988-1997 & All ages & CHCC/ACR & $8.7-10.3$ & $6.8-8.9$ & $1.5-3.7$ \\
\hline Watts et al. [13] & UK & $1990-2005$ & All ages & Clinical diagnosis & 8.4 & - & - \\
\hline Koldingsnes et al. [14] & Norway & $1984-1998$ & Age $>15$ years & ACR & $6.0-14.4$ & - & - \\
\hline Gonzales-Gay et al. [15] & Spain & 1998-2001 & Age $>15$ years & $\mathrm{CHCC}$ & 2.95 & 7.91 & 1.31 \\
\hline Reinhold-Keller et al. [16] & Germany & 1998-2002 & All ages & $\mathrm{CHCC}$ & $6-12$ & $2-3$ & $0-2$ \\
\hline Ormerod et al. [17] & Australia & 1995-2004 & Age $>15$ years & $\mathrm{ACR} / \mathrm{CHCC}$ & $8.4-8.8$ & $2.3-5$ & $2.2-2.3$ \\
\hline \multicolumn{8}{|l|}{ Paediatric cohort data } \\
\hline Gardner-Medwin et al. [18] & UK & 1996-1999 & Age $<17$ years & ACR & \multicolumn{3}{|c|}{$\begin{array}{l}\text { Primary systemic vasculitis incidence } 10.6 \text { per } \\
100,000 \text { patients (including } \\
\text { ANCA-vasculitis) }\end{array}$} \\
\hline Grisaru et al. [19] & Canada & $1994-2009$ & Age $<18$ years & ACR or EULAR/PRES & 6.39 & - & - \\
\hline
\end{tabular}

GPA, Granulomatosis with polyangiitis; MPA, microscopic polyangiitis; EGPA, eosinophilic granulomatosis with polyangiitis; CHCC, Chapel Hill Consensus conference; ACR, American College of Rheumatology; PRES, Paediatric Rheumatology European Society; EULAR European League Against Rheumatism; ANCA, anti-neutrophil cytoplasmic antibody

PR3-ANCA correlating with $H L A-D P$ and the $\alpha$-antitrypsin gene (SERPINA1, a serine proteinase inhibitor for which PR3 is one of the substrates) and proteinase 3 (PRTN3) and antiMPO-ANCA associated with $H L A-D Q$ [24].

\section{Clinical features}

The clinical features of disease in children and adults with GPA and MPA, respectively, in Table 2.

\section{Granulomatosis with polyangiitis}

The differences between paediatric GPA and MPA presentation and adult data are shown in Table 2 [27, 29]. In 2007 a collaboration between U.S. and Canadian centres led to the establishment of the ARChiVe (A Registry for Childhood Vasculitis: e-entry) vasculitis registry. This multi-centre group have since described the largest cohorts of paediatric GPA to date $[20,32]$.

Characteristic features of both adult and childhood GPA include necrotizing granulomata of the upper and lower respiratory tract, necrotizing vasculitis and glomerulonephritis (GN). Childhood GPA differs from adult GPA in several key features [5]. Childhood disease is frequently heralded by the presence of constitutional symptoms such as fever, anorexia and weight loss [1]. Multi-organ or generalized disease is common, consisting predominantly of ear, nose and throat $(80 \%)$, pulmonary $(80 \%)$ and renal $(75.4 \%)$ involvement, respectively. Less frequently involved are the musculoskeletal $(57 \%)$, gastrointestinal $(42 \%)$, eyes $(37 \%)$, skin (35\%) and nervous systems (25\%) [20].
Upper airway involvement in children is consistently reported at presentation, with an incidence of $70-100 \%$ [20, 32], commonly manifesting as recurrent epistaxis or sinusitis. Oral ulceration is also reported although without evidence of granulomata on biopsy [2]. Chronic inflammation can result in nasal septum perforation, saddle-nose deformity, chronic sinusitis and conductive hearing loss [1]. Respiratory symptoms described in the ACR-defined ARChiVe cohort and other studies include dyspnoea (59\%) and chronic cough (52\%), hoarseness (12\%), stridor (29\%) and haemoptysis (18\%), [2, 20].

In those children whose radiographs show changes, findings include diffuse pulmonary infiltrates, nodules, cavitating lesions and granulomata without cavitation. Pulmonary nodules and haemorrhage are reported with a similar incidence [1, 20]. Severe pulmonary haemorrhage requiring mechanical ventilation can occur in 16-20\% of patients at presentation. In comparison with adult disease, subglottic stenosis is a highly specific feature of paediatric GPA, reportedly affecting up to $50 \%$ of paediatric patients [33], and can present independently of systemic disease [34]. As such, it has been included in new classification criteria [5].

Renal manifestations of childhood GPA contribute to significant morbidity. Presentation can vary from urinary sediment abnormalities or mild renal dysfunction to acute kidney injury requiring renal replacement therapy (RRT) [1, 20, 32]. A diagnosis of glomerulonephritis based on biopsy findings is common. In a singlecentre review of biopsy-proven ANCA-associated glomerulonephritis, significant acute kidney injury [glomerular filtration rate (GFR) $<60 \mathrm{ml} / \mathrm{min} / 1.73 \mathrm{~m}^{2}$ ) and/or nephrotic-range proteinuria at presentation was found in 57\% (4 of 7) patients with childhood GPA [35]. 


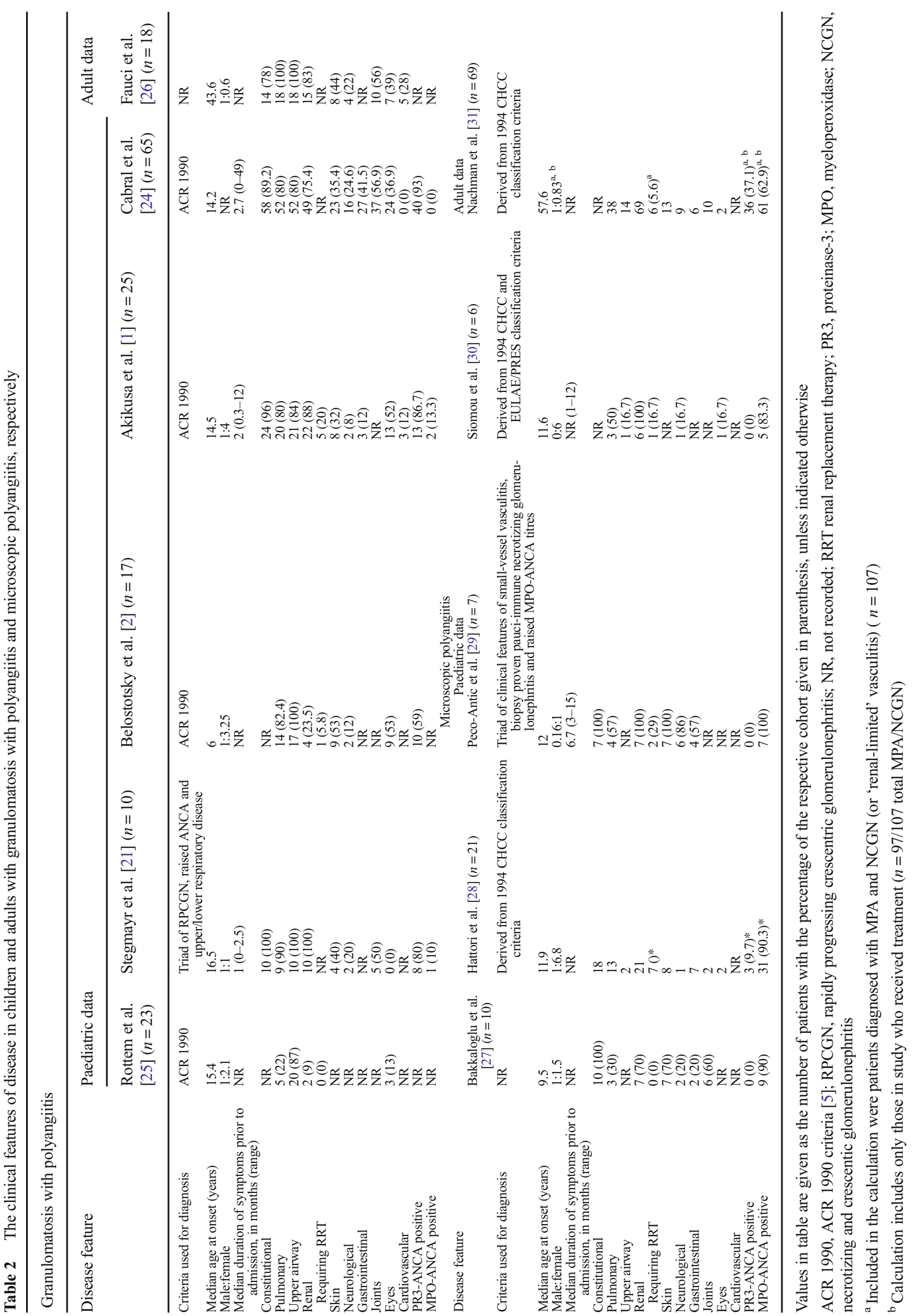


While numbers were limited, oliguria, markedly reduced GFR, nephrotic-range proteinuria and chronic glomerular lesions were associated with poorer outcomes [35].

Arthralgia and myalgia are reported in up to $64 \%$ of patients at presentation and are deemed to be early markers for disease flare. Arthritis is less common (20-32\%) and seen in the context of active disease [1]. Ocular involvement has been reported in up to $53 \%$ of paediatric patients. Inflammatory changes can occur in any compartment causing proptosis [36], conjunctivitis, episcleritis and uveitis. Venous thrombosis is an uncommon finding, having been reported in $12 \%$ of paediatric patients [1]. Cutaneous involvement affects up to $53 \%$ of patients at presentation and includes palpable purpura, which is often mistaken for immunoglobulin A (IgA) vasculitis (the new term for Henoch-Schönlein purpura), petechiae and nodules. Nervous system involvement is uncommon although symptoms can range from headache and dizziness to acute mononeuritis. Cerebellar involvement, seizures and upper motor neurone signs have all been described in children with GPA [1,2].

\section{Microscopic polyangiitis}

Microscopic polyangiitis is a rare disease in childhood and is characterized by a multi-system pauci-immune necrotizing small-vessel vasculitis without granulomatous inflammation. Prior to ARChiVe, evidence of paediatric presentation and disease course in MPA was limited [14, 15]. Recently, however, the ARChiVe Investigators Network described the largest paediatric MPA cohort to date (48 patients) using EMA criteria [32].

As with GPA, a female predominance is seen in childhood (as high as 6:1 [14]). Patients are significantly younger than those with GPA (11 vs. 14 years) [32]. Onset is insidious and associated with constitutional symptoms in almost all patients $[15,32]$. Purpuric rash at presentation is common although other skin lesions include necrotizing vasculitis and lesions mimicking pyoderma gangrenosum [14]. The incidence of central nervous system involvement has varied between cohorts, ranging from 21 to $86 \%$. In the cohort study by the ARChiVe Investigators Network symptoms included seizures, optic neuritis and peripheral neuropathy. Pulmonary symptoms including cough, haemoptysis and dyspnea were present in $44 \%$ of cases, although symptoms were less frequent and severe than in GPA patients. Using EMA criteria, gastrointestinal symptoms including chronic nausea and non-specific abdominal pain were also seen in the majority of patients (58\%) [32].

Renal involvement is common at presentation (75-90\%) [14] and often follows a more severe course than that seen in paediatric GPA [32, 35]. In the ARChiVe Investigators Network study, three-quarters of patients described using EMA criteria demonstrated renal involvement, with manifestations including proteinuria, microscopic haematuria and renal dysfunction with moderate to severely elevated serum creatinine levels ( $>30 \%$ age-adjusted upper limit of normal) in $48 \%$ of affected patients. Hypertension was noted in one-third of cases, while RRT was required in one-quarter of patients at presentation. Delay in diagnosis and higher Birmingham vasculitis activity scores (BVAS) have been associated with poor renal outcome [14].

Bakkaloglu et al. reported a high incidence of acute kidney injury at presentation (6/10 patients), with one-half of the patients requiring RRT in association with pulmonary involvement and high MPO-ANCA titres [150-250 endotoxin units $(\mathrm{EU}) / \mathrm{ml}$. All patients with pulmonary-renal involvement progressed to end-stage kidney disease (ESKD) within 1 to 5 years. Hypertension was present in $83 \%$ (5 of 6 ) MPA patients with renal involvement, with evidence of renal artery aneurysms in one patient [15].

\section{Renal limited vasculitis}

Renal limited vasculitis (RLV) is a term used for renal histopathology [previously classified as pauci-immune, necrotizing crescentic (NCGN) or ANCA-associated glomerulonephritis (AAGN)] in the absence of vasculitis in other organs. Approximately $80 \%$ of patients with RLV will be positive for ANCA, predominantly MPO-ANCA, and as such may be cohorted with patients diagnosed as MPA [37]. In children, AAGN is the second commonest cause of rapidly progressive glomerulonephritis (RPGN) behind immune-mediated pathologies, such as post-infectious, IgA vasculitis and IgA nephropathy. In a singlecentre study of RPGN, pauci-immune crescentic GN was observed in 31/73 patients aged between 1 and 20 years [37]. In a retrospective study for the Japanese Society of Paediatric Nephrology, Hattori et al. reported a mean age at presentation of 11.9 years (Table 2) and female preponderance (6.8:1). Of the ten patients described, seven were detected through national screening, while three presented with constitutional symptoms of malaise, anorexia, fever and weight loss. During a median follow-up period of 3.9 (range 1.3-4.9) years, no patients developed evidence of extra-renal disease [38].

\section{Eosinophilic granulomatosis with polyangiitis}

Eosinophilic granulomatosis with polyangiitis is extremely uncommon in children and is thought to contribute $2 \%$ of all paediatric PSV. It is a necrotizing vasculitis of small- and medium-sized vessels that predominantly affects the upper airways and lungs. Extra-pulmonary disease including cutaneous, cardiac, neurological and gastrointestinal involvement is common. The presence of ANCA is less common in paediatric EGPA than in adult patients, with $0-25 \%$ cases testing 
positive. To date, 47 cases have been published within the paediatric literature; none of which had evidence of renal involvement [39]. We therefore aim to focus further discussion within this review on the management of GPA and MPA only.

\section{Renal histology in AAV}

Renal biopsy remains the 'gold standard' in diagnosing AAGN. Classically, AAGN is characterized by a pauciimmune crescentic necrotizing glomerulonephritis on light microscopy. Histopathological features may vary, including acute lesions such as glomerular crescents or tubular intraepithelial infiltrates to lesions indicative of chronic inflammation, i.e. glomerulosclerosis, interstitial fibrosis or tubular atrophy [26]. Electron microscopy features include subendothelial oedema, microthrombi and degranulation of neutrophils [31]. While a paucity of immune deposits is considered typical, there are a few cases of childhood AAV in which immune deposition has been seen on examination by electron microscopy [35]. It is speculated that their presence may somehow potentiate the effect of ANCA in the development of glomerulonephritis [25].

Glomerulonephritis in MPA patients tends to be associated with a greater degree of chronic lesions, whereas a greater proportion of normal glomeruli are seen in GPA. In a paediatric study of MPA, findings included focal segmental necrosis of glomeruli among those children with a shorter duration between symptom onset and diagnosis, while those with greater delay demonstrated circumferential fibrous and/or fibro-cellular crescents [15]. This finding is supported by other studies $[35,38]$. Glomerulosclerosis is also more prominent in patients positive for MPO-ANCA, which suggests the pathogenesis of renal disease may differ between ANCA subtypes [26].

Adult studies have attempted to delineate the prognostic value of pathologic lesions on biopsy alongside patient demographics. Baseline GFR has been shown to correlate with renal function at 18 months of follow-up [40]. ANCA subtype was found not to be independently linked to renal prognosis. The percentage of normal glomeruli has been shown to strongly correlate with renal function [30] at baseline and follow-up [28]. In terms of acute lesions, the presence of cellular crescents is associated with improvements in renal function independent of baseline GFR, suggesting a potential reversibility of active disease [40]. Conversely, fibrous crescents correlate with RRT requirement at baseline and a poor renal outcome [28]. Chronic lesions including glomerular sclerosis and tubular atrophy, as well as degree of proteinuria at baseline relate to poor long-term outcomes [30, 41].
Collating this information, an international working group in 2010 proposed a new histopathologic classification for AAGN that features four distinct categories: focal, crescentic, mixed and sclerotic [42-44]. This classification system has since been validated in children with AAGN over a median follow-up period of 2.4 years, demonstrating a probability of an estimated GFR (eGFR) of $>60 \mathrm{ml} / \mathrm{min} / 1.73 \mathrm{~m}^{2}$ at 2 years as $100 \%$ for focal lesions, $56.5 \%$ for crescentic/mixed and $0 \%$ for sclerotic biopsy categories [45].

\section{Measurement of disease activity}

Formal measurement of disease activity is essential to assess treatment efficacy in clinical practice and therapeutic trials. In adults, the BVAS and Vasculitis Activity Index are disease tools that have been validated in AAV $[46,47]$. These tools have undergone a number of changes, including disease-specific modifications for GPA (formerly known as BVAS-WG).

Recently International collaborative working groups have emphasized the need to develop a robust paediatric-specific disease measurement tool. The development of the Paediatric Vasculitis Activity Scale has shown strong correlation with physician assessment, erythrocyte sedimentation rate and treatment decision, as well as high agreement between assessors [48].

\section{Investigations}

Primary systemic vasculitis should be considered in any child presenting with a multi-system disease. Investigations which should be performed in children when there is a suspicion of AAV are listed in Table 3. It is important to exclude differential diagnoses such as infection or malignancy.

Immunological testing is important in the work-up of ANCA-associated and PSV. ANCA positivity by enzymelinked immunosorbent assay or indirect immunofluorescence testing in the paediatric population has a sensitivity $93 \%$ and specificity of $90 \%$ [5]. GPA is frequently associated with elevated titres of ANCA directed at PR3 that lead to cytoplasmic staining of neutrophils (cANCA), whilst MPA is frequently associated with antibody directed against MPO that stains neutrophils in a perinuclear fashion (pANCA) [49].

Glomerulonephritis may present as haematuria and/or proteinuria on dipstick testing, or in a more pronounced fashion, with hypertension, oligo-anuria and/or nephrotic-range proteinuria. Early renal biopsy should be considered in patients with renal involvement. 
Table 3 Suggested investigations in suspected antineutrophil cytoplasmic antibodyassociated vasculitis

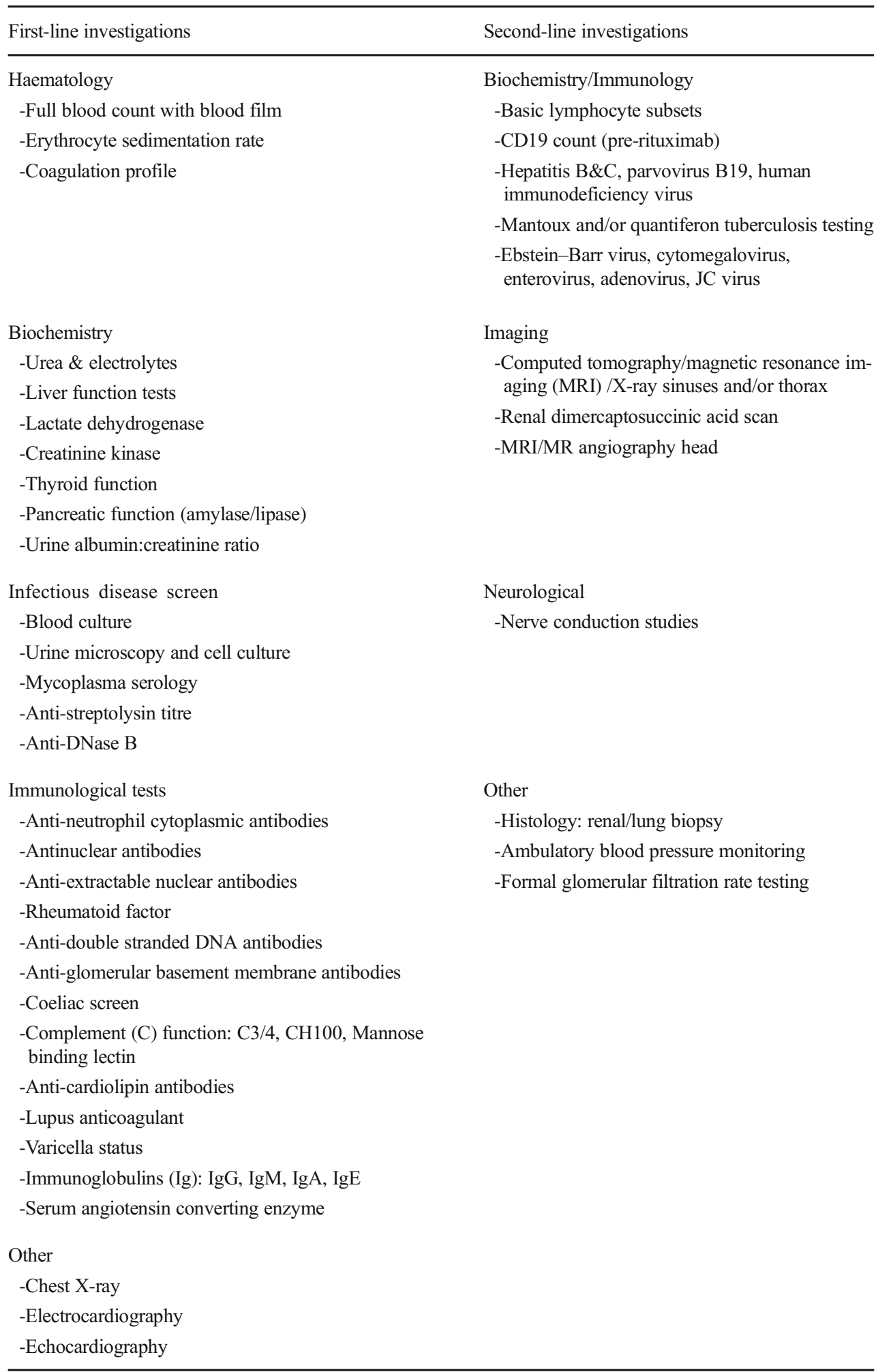

\section{Management}

Modern immunosuppression has increased the survival rates of patients with AAV. Treatment is based on intensive remission induction followed by maintenance therapy.
At present, there are very little data to allow the development of a paediatric-specific AAV guideline. The SHARE project, a European initiative, aims to provide treatment recommendations for the care of children and young adults with vasculitis. These recommendations are currently awaited and 
will be based on surveys sent to PRINTO members of current clinical practice and systematic literature reviews [50]. Therefore, this review will provide information based on the authors' experience and the evidence obtained from the limited number of randomized controlled trials (RCTs) performed in adults extrapolated to children (Fig. 1). While GPA and MPA are considered separate entities, the two are managed identically with regards to therapeutic intervention.

A recent study from the ARChiVE group demonstrated significant concordance between treatment intensity and the European Vasculitis Study Group (EUVAS) subgroupings in 125 paediatric patients [51]. Therefore, we used these disease categories to describe therapeutic options (Table 4).

\section{Remission induction}

The initial goal of therapy in AAV is to achieve remission, formally defined using disease activity tools. Traditionally severe disease including renal involvement has been managed with the 'gold standard' treatment of glucocorticoids and cyclophosphamide, with remission rates of between 70 and100\% [43, 52-54]. Other agents employed in remission induction include TNF- $\alpha$ therapy and mycophenolate mofetil (MMF). Recently, however, increasing consideration is being given to rituximab as an equally effective therapy in severe or relapsing therapy, particularly for those patients at risk for glucocorticoid or cyclophosphamide toxicity.

Patients with severe or generalized disease have historically received large amounts of immunosuppression given their poor prognosis, including intravenous (IV) cyclophosphamide and methylprednisolone [52]. In such cases, adjuvant therapy in the form of plasma exchange has been shown to increase the renal survival in this cohort [53].

\section{Cyclophosphamide}

Cyclophosphamide is an alkylating agent that has long held a key role in the remission induction and maintenance of PSV and AAV. However, concerns do exist regarding cumulative toxicity, particularly in children. High cumulative doses can result in unacceptable adverse events, such as haemorrhagic cystitis $(43 \%)$, infertility ( $57 \%$ of females), opportunistic infections (0.11 infections per patient-year) and a 2.4-fold increased risk of malignancy, among others [54].

Research has focused on minimizing cumulative doses, as well as determining equally effective alternatives. In AAV, a meta-analysis has confirmed that IV cyclophosphamide pulse therapy is as effective as cyclophosphamide administered as daily doses and results in a smaller cumulative dose with fewer adverse effects $[55,56]$.
Remission Induction

Localised disease:

Methotrexate and glucocorticoid therapy

- Methotrexate $\left(10-15 \mathrm{mg} / \mathrm{m}^{2} /\right.$ dose) PO or SC weekly

- PO prednisolone $\left(30-60 \mathrm{mg} / \mathrm{m}^{2} /\right.$ day or $1-2 \mathrm{mg} / \mathrm{kg}$ ) for a total of 4 weeks before tapering over the following 6-8 weeks (depending on response to treatment). Aim to wean to $0.5 \mathrm{mg} / \mathrm{kg} /$ alternate day dosing.

Generalised disease:

Pulsed IV cyclophosphamide + methylprednisolone therapy

- IV cyclophosphamide $0.5-1 \mathrm{~g} / \mathrm{m}^{2}$ monthly (with mesna to prevent cystitis) for 6 months. Alternative is oral cyclophosphamide dosing (2-3mg/kg once daily for 2-3 months).

- IV methylprednisolone $30 \mathrm{mg} / \mathrm{kg}$ (max $1 \mathrm{~g}$ ) once daily for three doses before conversion to oral prednisolone (as above).

Severe/ renal or life-threatening disease/refractory disease: Consider Rituximab, IV cyclophosphamide, plasma exchange (PEX), and/or IVIg alongside pulsed IV methylprednisolone.

- Rituximab: $750 \mathrm{mg} / \mathrm{m}^{2} /$ dose IV (max $1000 \mathrm{mg}$ )- for two doses two weeks apart.

- Plasma exchange: 5 or 10-day course of 2-volume PEX with 4.5\% Human albumin solution.

- IVlg: $2 \mathrm{~g} / \mathrm{kg}$.

\section{Maintenance therapy}

Localised/Early systemic disease:

- Methotrexate (as above) or Azathioprine $(0.5-2.5 \mathrm{mg} / \mathrm{kg}$ once daily PO for 1 year or more) with steroid tapering.

- Azathioprine (as above)

- Aim to wean steroids to maintenance dose of $0.5 \mathrm{mg} / \mathrm{kg} /$ alternate days, or off completely if stable.

Second line therapy

Localised/Early systemic:

Consider leflunamide, MMF

Generalised:

Consider rituximab, infliximab, MMF, oral cyclophosphamide

Fig. 1 A treatment algorithm for anti-neutrophil cytoplasmic antibodyassociated vasculitis according to the severity of the presenting disease and the treatment for both remission induction and maintenance of disease. PO Oral, SC subcutaneous, IV intravenous, IVIg intravenous immunoglobulin, $M M F$ mycophenolate mofetil

\section{Anti-TNF- $\alpha$ therapy}

In $\mathrm{AAV}$, it is thought that TNF- $\alpha$ is likely to play a role in neutrophil priming, resulting in the expression of endothelial adhesion molecules and ANCA antigens on the cell surface [18]. The Wegener's granulomatosis etanercept trial (WGET) assessed the efficacy of etanercept, a TNF- $\alpha$ blocker, in remission induction and remission maintenance of GPA [57, 58]. A total of 108 patients were randomized to receive either etanercept or placebo in addition to standard therapy (cyclophosphamide and corticosteroids for severe disease or methotrexate and corticosteroids for limited disease). No difference in remission induction rates were seen between the two groups 
Table 4 European Vasculitis Study Group definitions used in cases of anti-neutrophil cytoplasmic antibody-associated vasculitis based on the severity and extent of disease

\begin{tabular}{ll}
\hline Category & Description \\
\hline Localized & $\begin{array}{c}\text { Upper and/or lower respiratory symptoms without other system involvement or constitutional } \\
\text { symptoms }\end{array}$ \\
Early systemic & $\begin{array}{c}\text { Disease without threatened organ function or life-threatening disease (also known as } \\
\text { 'non-organ or life threatening' }\end{array}$ \\
Generalized & $\begin{array}{l}\text { Renal, or other organ-threatening disease. Serum creatinine }<500 \mu \mathrm{mol} / \mathrm{l}(\mathrm{or} 5.6 \mathrm{mg} / \mathrm{dl}) \\
\text { Severe } \\
\text { 'immediately life threatening' }\end{array}$ \\
Refractory & Disease unresponsive to glucocorticoids and cyclophosphamide \\
\hline
\end{tabular}

although an increase in solid cancers was noted in those patients receiving standard therapy combined with cyclophosphamide, suggesting a cumulative malignancy risk. Relapse rates during maintenance therapy were similar.

Interestingly, whilst inhibition of TNF- $\alpha$ via etanercept has shown no benefit in remission induction for either early systemic or generalized disease, anti-TNF- $\alpha$ antibodies, such as infliximab and adalimumab, do show promise. In an openlabel prospective trial of $16 \mathrm{AAV}$ adults with renal involvement, adjuvant infliximab therapy was noted to achieve a mean timeto-remission of 6.4 weeks when used alongside cyclophosphamide and enabled a significant reduction of steroid doses [59]. However, there have been no RCTs to confirm this finding to date. The results of a prospective open-label study of adjuvant adalimumab suggest that while remission rates are similar to those seen with standard therapy alone ( $78.5 \%$ by week 14$)$, a significant steroid-sparing effect is present [60].

\section{Mycophenolate mofetil}

At present, there is limited evidence to support the use of MMF in induction regimens for AAV. Recently, the results of a non-inferiority trial were reported ('MYCYC'; a randomized control trial of MMF vs. cyclophosphamide in remission induction in AAV) [61]. The study comprised 140 newly diagnosed patients (70 per arm), including paediatric patients. The primary outcome was remission, defined as absence of disease activity for longer than 4 weeks when adhering to the glucocorticoid regimen. The study was unable to demonstrate that MMF is non-inferior to cyclophosphamide when adherence is taken into account; however, the authors conclude that further evaluation of how glucocorticoid treatment affects remission induction is warranted [61].

\section{Plasma exchange}

Removal of circulating ANCA through plasma exchange is a short-term measure often reserved for severe or refractory disease. It should be used in conjunction with immunosuppression. The MEPEX trial consisted of 137 patients with severe renal vasculitis who were randomized to receive plasma exchange versus pulsed methylprednisolone [44]. The results demonstrated a $50 \%$ relative reduction in the need for RRT at 12 months in those who received plasma exchange, with no difference in the frequency of adverse effects. The authors of a meta-analysis of nine studies concluded that while renal survival with plasma exchange is encouraging (overall relative risk of renal disease following adjuvant therapy $0.64,95 \%$ confidence interval $0.47-0.88, p=0.006$ ), there is insufficient evidence to suggest whether it improves overall survival [53, $62]$, highlighting the need for larger studies. At the present time there is little evidence of the effect of plasma exchange on extra-renal manifestations [63]. An international open label study is currently recruiting to address these questions [64]. With the aim of recruiting 700 patients, 'PEXIVAS' is a randomized trial with the intent to compare adjuvant plasma exchange and two oral glucocorticoid regimens in patients undergoing remission induction treatment, including adolescents (aged $>15$ years). The primary outcome measure is mortality from any cause and ESKD [64].

\section{Maintenance therapy}

Studies have confirmed findings that cyclophosphamide can safely be substituted for maintenance azathioprine, thereby avoiding large cumulative doses and their associated toxicity [43]. Other options for remission maintenance in milder disease without renal involvement include methotrexate and leflunamide. MMF may be considered for patients in whom azathioprine is poorly tolerated, although it appears less efficacious [65].

\section{Azathioprine}

In terms of the maintenance of disease control, the CYCAZAREM trial (randomized trial of Cyclophosphamide versus Azathioprine during Remission in ANCA-positive systemic vasculitis) demonstrated no significant differences in rates of relapse between patient groups at 18 months [15.5 vs. $13.7 \%$ in cyclophosphamide and azathioprine (AZA) groups, respectively] [43]. Subsequent retrospective studies with longer follow-up periods demonstrated a slightly higher relapse rate in 
patients treated with azathioprine ( 42.3 vs. $57.4 \%$ ) at 5 years [66]. Many of the relapses reported however occurred following discontinuation of therapy and were more frequent in patients positive for PR3-ANCA when starting therapy.

\section{Mycophenolate mofetil}

The IMPROVE study (International MMF Protocol to Reduce Outbreaks of Vasculitides), an open-label, multi-center RCT, was designed to assess whether MMF reduced the risk of relapse compared with azathioprine for AAV patients in remission [65]. The results demonstrated an inferior effect to that of AZA in sustaining disease-free survival (55.3 vs. $37.5 \%$ ). No differences in the number of adverse effects were reported, but in view of these results, AZA is generally preferred over MMF for remission maintenance. As an alternative, and in those with milder disease (including adequate renal function), methotrexate may be safely used for maintenance of remission in this cohort [63]. Leflunamide is reported to be more efficacious than methotrexate, but it is associated with greater adverse effects [67].

\section{Management of refractory disease}

Similar to severe disease, progressive, unresponsive disease in $\mathrm{AAV}$ is associated with significant mortality that is both diseaseand therapy-related. In these circumstances, further courses of induction treatments should be considered, such as IV cyclophosphamide, methylprednisolone, infliximab, and plasma exchange. Biologic agents play a significant role in these patients.

\section{Rituximab}

There is increasing evidence that rituximab has a short- and medium-term benefit in both severe and refractory disease. For children who are at particular risk of toxicity from both cyclophosphamide and corticosteroids, rituximab is likely to provide an alternative, equally efficacious means by which disease activity can be managed. In AAV, chronic T-cell activation is thought to promote maturation of auto-reactive B cells, which in turn leads to the production of ANCA. Rituximab, a chimeric monoclonal anti-CD20 antibody, causes $\mathrm{B}$ cell depletion and has been evaluated in two RCTs for remission induction-RAVE and RITUXVAS [68, 69]. A further evaluation of its use in remission maintenance, the MAINRITSAN study, has also been published with positive results [70].

The RAVE trial (Rituximab in ANCA-associated Vasculitis) was a multi-center RCT designed to assess the use of rituximab versus cyclophosphamide in remission induction [69]. New patients or those with relapsing disease were randomized to receive either rituximab $\left(375 \mathrm{mg} / \mathrm{m}^{2} \mathrm{IV}\right.$ weekly for 4 weeks) or oral cyclophosphamide ( $2 \mathrm{mg} / \mathrm{kg} /$ day). Patients with severe renal disease were excluded. Patients in the cyclophosphamide arm who achieved remission between 3 and 6 months were eligible to switch to AZA for the remainder of the study whilst the rituximab group received placebo. A total of 197 AAV patients were recruited. Rituximab was found to be non-inferior when compared with cyclophosphamide for achieving disease remission by 6 months. In patients with relapsing disease, rituximab was superior. No difference was seen with regards to adverse effects or steroid exposure.

The RITUXVAS trial compared rituximab $\left(375 \mathrm{mg} / \mathrm{m}^{2}\right.$ IV weekly for 4 weeks administered with $2 \times 15 \mathrm{mg} / \mathrm{kg}$ IV cyclophosphamide) to the 'gold standard' IV cyclophosphamide regimen $(6-10$ doses at $15 \mathrm{mg} / \mathrm{kg}$ ) for new AAV patients and included those with renal involvement [68]. The results demonstrated that rituximab is as effective as cyclophosphamide in inducing remission, with both achieving high remission rates (76\% in rituximab arm vs. $82 \%$ in cyclophosphamide arm). Similar numbers of adverse effects were reported (18\% mortality in both treatment arms). Further data from the RITUXVAS group at 2 years of follow-up has revealed no differences between rituximab and control with regards to a composite outcome of death, ESKD or relapse. While no relapses were demonstrated in B-cell-depleted patients, B-cell return alone was not felt to be a sufficient marker for potential relapse: only $30 \%$ of patients with B-cell return had a confirmed clinical relapse. No differences in patients achieving ANCA negativity were noted ( $88 \%$ in rituximab vs. $73 \%$ in cyclophosphamide group) [71].

Subsequent prospective data from the RAVE group demonstrates that there is no difference in remission rates when rituximab was given to patients from both treatment arms for relapse. This result suggests that the effect of rituximab is not dependent on the initial remission-induction agent used. Again, ANCA and B-cell counts were not predictive of relapse [72].

With respect to remission maintenance, rituximab has been compared in a non-blinded RCT with AZA in the MAINRTISAN study (Maintenance of Remission using Rituximab in Systemic ANCA-associated vasculitis) [70]. Eligible patients included those with biopsy-proven ANCApositive GPA, MPA or renal-limited AAV. Following the induction of remission, patients were randomized to receive either fixed doses of rituximab $500 \mathrm{mg}$ at days 0 and 14 and months 6 , 12 and 18 after first infusion, or control AZA at $2 \mathrm{mg} / \mathrm{kg}$ daily for 12 months, followed by $1.5 \mathrm{mg} / \mathrm{kg}$ daily for a further 6 months. The primary outcome was percentage of patients who experienced a major relapse (BVAS score $>0$ and involvement of one major organ) at month 28. A total of 115 patients underwent randomization, with each group having similar baseline characteristics and proportions of relapsing disease. There were fewer major relapses in the rituximab group than in the control group (hazard ratio for relapse 6.61, 95\% confidence interval 1.56-27.96, $p=0.002$ ), with similar severe adverse effects noted in both groups.

An international open-label RCT comparing rituximab and AZA as maintenance therapy in relapsing AAV is currently 
recruiting (the 'RITZAREM' study). Remission induction will be achieved with rituximab $\left(4 \times 375 \mathrm{mg} / \mathrm{m}^{2}\right)$ followed by randomization to fixed-interval repeat dosing or AZA for 24 months. It is anticipated that 160 patients will be recruited for a follow-up study period of 4 years. Retrospective evidence suggests fixed-interval dosing confers a greater clinical benefit to patients without additional adverse effects, although randomized studies are required to confirm this finding [73].

In refractory disease, adjuvant therapy with infliximab or rituximab alongside conventional immunosuppression has been compared in a prospective RCT. Although the trial involved only a small number of patients, results suggested rituximab was more effective at obtaining and sustaining remission over a mean follow-up of 31 months [74].

Rituximab use has been described in 13 paediatric patients. In one study, the administration of rituximab resulted in significantly improved BVAS scores and enabled steroid weaning in four children with GPA [75]. Other case series report high remission rates for both GPA and MPA even when conventional treatments have failed. A phase IIa international multi-center open-label trial is currently ongoing to evaluate the safety and pharmacokinetics of rituximab in children with severe AAV (The 'PEPRS' study; NCT01750697). Newly diagnosed patients or those with relapsing disease who have not previously received rituximab will be eligible for inclusion. Recruitment commenced in 2013 and follow-up will continue for approximately 3.5 years.

Current expert consensus recommends the use of rituximab for remission induction in refractory disease, or where there are concerns regarding cumulative cyclophosphamide or corticosteroid toxicity, particularly in children [76, 77]. Recommendations also include repeat treatment where relapse occurs following a rituximab-induced remission.

\section{Immunoglobulin}

Intravenous immunoglobulin (total dose $2 \mathrm{~g} / \mathrm{kg}$ ) as adjuvant therapy was effective at producing a significant short-term improvement in disease activity compared with placebo in a RCT [78]. However, the effect was short lived, and no differences between groups were noted at 3 months.

\section{Future therapies}

Given the success of rituximab, further work is ongoing to identify alternative therapies for B-cell depletion. A novel fully humanized monoclonal anti-CD20 antibody, ocrelizumab, has been trialed in rheumatoid arthritis [79]. Initial safety data suggest that ocrelizumab is well tolerated, rapidly depletes $\mathrm{B}$ cells with clinical improvement and has similar adverse effects when compared with standard treatment.

\section{Renal transplantation in $\mathbf{A A V}$}

Despite improved recognition and management of the AAV, progression to ESKD still occurs in a significant proportion of patients. While the paediatric literature is limited, both renal and non-renal relapses have been reported in adult patients with GPA, MPA and RLV. In a pooled analysis of published data, the recurrence rate for adults post-renal transplantation was reported to be $17.3 \%$ (127 patients), with no differences in relapse rate noted between the three disease entities. Average time from transplant to relapse was 31 months. Duration of time on dialysis, ANCA subtype, ANCA positivity at time of transplantation, allograft type (deceased or live) and immunosuppression regimen (with or without ciclosporin) had no clear effect on relapse rate [80].

More recently, a large retrospective study of 85 patients reported a low relapse rate of 0.02 per patient-year (median follow-up 64 months, range 3-165 months) on a prednisolone, MMF and tacrolimus regimen post-transplantation, with lower relapse rates than in patients on dialysis, perhaps the result of immunosuppression regimens used post-transplantation [81]. Renal function post-transplantation is also comparable to control subjects, with similar patient and graft survival rates seen at 1, 5 and 10 years of follow-up [81, 82]. Therefore, despite the perpetual risk of relapse, kidney transplantation is recommended for patients with ESKD during clinical remission, regardless of ANCA status [80, 81].

\section{Prognosis}

Most of our knowledge regarding the long-term outcomes of AAV is based on adult data. In children, the majority of studies have a limited follow-up: to date, seven case series describe a total of 86 paediatric patients with AAV, with follow-up periods ranging from 4 months to 11 years. Compared with adult data, long-term disease or treatment-related morbidity is reportedly lower (22 vs. $45 \%$ [33]), however the data are weak and the burden is still significant. A recent study of children followed up into adulthood (median of 18.5 years, range 1130 years [3]) described eight patients with relapsing disease. One death was noted secondary to respiratory complications of GPA. With regards to treatment-related morbidity, $50 \%$ of patients were infertile, 7 patients suffered infections, one patient developed a malignancy and two developed skeletal complications secondary to corticosteroid treatment. Onehalf of all patients developed ears, nose, and throat complications, including hearing loss (4 patients), nasal septum ( 2 patients) or upper airway deformities (1 patient). All but one patient had received cyclophosphamide, with five patients requiring repeated courses. Biological agents were used in three patients, with higher rates of infection seen with infliximab. The study emphasizes the need for effective 
immunosuppressive regimens while minimizing adverse effects: paediatric patients are at potentially greater risk of long-term morbidity due to their age and cumulative exposure and are therefore likely to benefit most from further research in this field.

\section{Conclusion}

Anti-neutrophil cytoplasmic antibody-associated vasculitis is a rare condition in children, but one that is associated with significant morbidity and mortality. The exact pathogenesis remains unknown, and it is likely to be multifactorial. Understanding some of the immune mechanisms underlying the disease has led to the addition of biologic therapies as feasible management options. The evidence base for management, especially in children, is limited; however, early aggressive immunosuppression is strongly recommended to achieve a prompt disease remission, and subsequent careful monitoring is required to assess for disease relapse. European initiatives may provide standardized guidance on management in the near future. Renal involvement is often associated with a worse long-term outcome, although renal transplantation remains an option in those who progress to ESKD.

Acknowledgements This project was supported by the National Institute for Health Research Biomedical Research Centre at Great Ormond Street Hospital for Children NHS Foundation Trust and University College London.

\section{Compliance with ethical standards}

Conflict of interest The authors declare no conflicts of interest.

Open Access This article is distributed under the terms of the Creative Commons Attribution 4.0 International License (http:// creativecommons.org/licenses/by/4.0/), which permits unrestricted use, distribution, and reproduction in any medium, provided you give appropriate credit to the original author(s) and the source, provide a link to the Creative Commons license, and indicate if changes were made.

\section{References}

1. Akikusa JD, Schneider R, Harvey EA, Hebert D, Thorner PS, Laxer RM, Silverman ED (2007) Clinical features and outcome of pediatric Wegener's granulomatosis. Arthritis Rheum 57(5):837-844

2. Belostostky VM, Shah V, Dillon MJ (2002) Clinical features in 17 paediatric patients with Wegener granulomatosis. Pediatr Nephrol 17:754-761

3. Arulkumaran N, Jawad S, Smith SW, Harper L, Brogan P, Pusey CD, Salama AD (2011) Long- term outcome of paediatric patients with ANCA vasculitis. Pediatr Rheumatol Online J 9:12. http://www.ped-rheum.com/content/9/1/12

4. Ozen S, Ruperto N, Dillon MJ, Bagga A, Barron K, Davin JC, Kawasaki T, Lindsley C, Petty RE, Prieur AM, Ravelli A, Woo P
(2006) EULAR/PReS endorsed consensus criteria for the classification of childhood vasculitides. Ann Rheum Dis 65(7):936-941

5. Ozen S, Pistorio A, Iusan SM, Bakkaloglu A, Herlin T, Brik R, Buoncompagni A, Lazar C, Bilge I, Uziel Y, Rigante D, Cantarini L, Hilario MO, Silva CA, Alegria M, Norambuena X, Belot A, Berkun Y, Estrella AI, Olivieri AN, Alpigiani MG, Rumba I, Sztajnbok F, Tambic-Bukovac L, Breda L, Al-Mayouf S, Mihaylova D, Chasnyk V, Sengler C, Klein-Gitelman M, Djeddi D, Nuno L, Pruunsild C, Brunner J, Kondi A, Pagava K, Pederzoli S, Martini A, Ruperto N, Paediatric Rheumatology International Trials Organisation (PRINTO) (2010) EULAR/PRINTO/PRES criteria for Henoch-Schönlein purpura, childhood polyarteritis nodosa, childhood Wegener granulomatosis and childhood Takayasu arteritis: Ankara 2008. Part II: Final classification criteria. Ann Rheum Dis 69:798-806

6. Watts R, Lane S, Hanslik T, Hauser T, Hellmich B, Koldingsnes W, Mahr A, Segelmark M, Cohen-Tervaert JW, Scott D (2007) Development and validation of a consensus methodology for the classification of the ANCA-associated vasculitides and polyarteritis nodosa for epidemiological studies. Ann Rheum Dis 66:222-227

7. Uribe AG, Huber AM, Kim S, O'Neil KM, Wahezi DM, Abramson L, Baszis K, Benseler SM, Bowyer SL, Campillo S, Chira P, Hersh AO, Higgins GC, Eberhard A, Ede K, Imundo LF, Jung L, Kingsbury DJ, Klein-Gitelman M, Lawson EF, Li SC, Lovell DJ, Mason T, McCurdy D, Muscal E, Nassi L, Rabinovich E, Reiff A, Rosenkranz M, Schikler KN, Singer NG, Spalding S, Stevens AM, Cabral DA, ARegistry for Children with Vasculitis e-entry (ARChiVe) Network (2012) Increased sensitivity of the European Medicines Agency algorithm for classification of childhood granulomatosis with polyangiitis. J Rheumatol 39(8):1687-1697

8. Jennette JC, Falk RJ, Bacon PA, Basu N, Cid MC, Ferrario F, Flores-Suarez LF, Gross WL, Guillevin L, Hagen EC, Hoffman GS, Jayne DR, Kallenberg CG, Lamprecht P, Langford CA, Luqmani RA, Mahr AD, Matteson EL, Merkel PA, Ozen S, Pusey CD, Rasmussen N, Rees AJ, Scott DG, Specks U, Stone JH, Takahashi K, Watts RA (2013) 2012 Revised International Chapel Hill Consensus Conference Nomenclature of Vasculitides. Arthritis Rheum 65(1):1-11

9. Basu N, Watts R, Bajema I, Baslund B, Bley T, Boers M, Brogan P, Calabrese L, Cid MC, Cohen-Tervaert JW, Flores-Suarez LF, Fujimoto S, de Groot K, Guillevin L, Hatemi G, Hauser T, Jayne D, Jennette C, Kallenberg CG, Kobayashi S, Little MA, Mahr A, McLaren J, Merkel PA, Ozen S, Puechal X, Rasmussen N, Salama A, Salvarani C, Savage C, Scott DG, Segelmark M, Specks U, Sunderköetter C, Suzuki K, Tesar V, Wiik A, Yazici H, Luqmani R (2010) EULAR points to consider in the development of classification and diagnostic criteria in systemic vasculitis. Ann Rheum Dis 69:1744-1750

10. Gardner-medwin JMM, Dolezalova P, Cummins C, Southwood TR (2002) Incidence of Henoch-Schönlein purpura, Kawasaki disease, and rare vasculitides in children of different ethnic origins. Lancet 360:1197-1202

11. Stegmayr BG, Gothefors L, Malmer B, Müller Wiefel DE, Nilsson K, Sundelin B (2000) Wegener granulomatosis in children and young adults. A case study of ten patients. Pediatr Nephrol 14(3): 208-213

12. Grisaru S, Yuen GWH, Miettunen PM, Lorraine A (2013) Incidence of Wegener's granulomatosis in children. J Rheumatol 37(2):440-442

13. Mahr AD, Neogi T, Merkel PA (2006) Epidemiology of Wegener's granulomatosis: lessons from descriptive studies and analyses of genetic and environmental risk determinants. Clin Exp Rheumatol Suppl 41:S82-91

14. Peco-Antic A, Bonaci-Nikolic B, Basta-Jovanovic G, Kostic M, Markovic-Lipkovski J, Nikolic M, Spasojevic B (2006) 
Childhood microscopic polyangiitis associated with MPO-ANCA. Pediatr Nephrol 21:46-53

15. Bakkaloglu A, Ozen S, Baskin E, Besbas N, Gur-Guven A, Kasapçopur O, Tinaztepe K (2001) The significance of antineutrophil cytoplasmic antibody in microscopic polyangitis and classic polyarteritis nodosa. Arch Dis Child 85:427-430

16. Gibelin A, Maldini C, Mahr A (2011) Epidemiology and etiology of Wegener granulomatosis, microscopic polyangiitis, ChurgStrauss syndrome and Goodpasture syndrome: vasculitides with frequent lung involvement. Semin Respir Crit Care Med 32(3): 264-273

17. Mahr A, Guillevin L, Poissonnet M, Aymé S (2004) Prevalences of polyarteritis nodosa, microscopic polyangiitis, Wegener's granulomatosis, and Churg-Strauss syndrome in a French urban multiethnic population in 2000: a capture-recapture estimate. Arthritis Rheum 51(1):92-99

18. Kallenberg CGM (2011) Pathogenesis of ANCA-associated vasculitides. Ann Rheum Dis 70 [Suppl 1]:i59-63

19. Kallenberg CGM, Heeringa P, Stegeman CA (2006) Mechanisms of Disease: pathogenesis and treatment of ANCA-associated vasculitides. Nat Clin Pract Rheumatol 2(12):661-670

20. Cabral DA, Uribe AG, Benseler S, O’Neil KM, Hashkes PJ, Higgins G, Zeft AS, Lovell DJ, Kingsbury DJ, Stevens A, McCurdy D, Chira P, Abramson L, Arkachaisri T, Campillo S, Eberhard A, Hersh AO, Huber AM, Kim S, Klein-Gitelman M, Levy DM, Li SC, Mason T, Dewitt EM, Muscal E, Nassi L, Reiff A, Schikler K, Singer NG, Wahezi D, Woodward A, ARChiVe (A Registry for Childhood Vasculitis: e-entry) Investigators (2009) Classification, presentation, and initial treatment of Wegener's granulomatosis in childhood. Arthritis Rheum 60(11):3413-3424

21. Falk RJ, Terrell RS, Charles LA, Jennette JC (1990) Anti-neutrophil cytoplasmic autoantibodies induce neutrophils to degranulate and produce oxygen radicals in vitro. Proc Natl Acad Sci USA 87(11): 4115-4119

22. Stegeman CA, Tervaert JW, de Jong PE, Kallenberg CG, for the Dutch Co-trimoxazole Wegener Study Group (1996) Trimethoprim-sulfamethoxazole (co-trimoxazole) for the prevention of relapses of Wegener's granulomatosis. N Engl J Med 335(1):16-20.

23. Zycinska K, Wardyn KA, Zielonka TM, Krupa R, Lukas W (2009) Co-trimoxazole and prevention of relapses of PR3-ANCA positive vasculitis with pulmonary involvement. Eur J Med Res 14[Suppl 4]:265-267

24. Lyons PA, Rayner TF, Trivedi S, Holle JU, Watts RA, Jayne DR, Baslund B, Brenchley P, Bruchfeld A, Chaudhry AN, Cohen Tervaert JW, Deloukas P, Feighery C, Gross WL, Guillevin L, Gunnarsson I, Harper L, Hrušková Z, Little MA, Martorana D, Neumann T, Ohlsson S, Padmanabhan S, Pusey CD, Salama AD, Sanders JS, Savage CO, Segelmark M, Stegeman CA, Tesař V, Vaglio A, Wieczorek S, Wilde B, Zwerina J, Rees AJ, Clayton DG, Smith KG (2012) Genetically distinct subsets within ANCAassociated vasculitis. N Engl J Med 367(3):214-223

25. Haas M, Eustace JA (2004) Immune complex deposits in ANCAassociated crescentic glomerulonephritis: A study of 126 cases. Kidney Int 65:2145-2152

26. Hauer HA, Bajema IM, Van Houwelingen HC, Ferrario F, Noël LH, Waldherr R, Ayne DR, Rasmussen N, Bruijn JA, Hagen EC, European Vasculitis Study Group (2002) Renal histology in ANCA-associated vasculitis: Differences between diagnostic and serologic subgroups. Kidney Int 61:80-89

27. Fauci AS, Wolff SM (1973) Wegener's granulomatosis: studies in eighteen patients and a review of the literature. Medicine 52(6): 535-561

28. de Lind van Wijngaarden RAF (2006) Clinical and histologic determinants of renal outcome in ANCA-associated vasculitis: a prospective analysis of 100 patients with severe renal involvement. J Am Soc Nephrol 17(8):2264-2274

29. Nachman H, Hogan SL, Jennette JC, Falk RJ (1996) Treatment response and relapse in antineutrophil cytoplasmic autoantibodyassociated microscopic polyangiitis and glomerulonephritis. J Am Soc Nephrol 7:33-39

30. Bajema IM, Christiaan Hagen E, Hermans J, Noël LH, Waldherr R, Ferrario F, Van Der Woude FJ, Bruijn JA (1999) Kidney biopsy as a predictor for renal outcome in ANCA-associated necrotizing glomerulonephritis. Kidney Int 56(5):1751-1758

31. Joh K, Muso E, Shigematsu H, Nose M, Nagata M, Arimura Y, Yumura W, Wada T, Nitta K, Makino H, Taguma Y, Kaneoka H, Suzuki Y, Kobayashi M, Koyama A, Usui J, Hashimoto H, Ozaki S, Tomino Y, Yamagata K (2008) Renal pathology of ANCA-related vasculitis: proposal for standardization of pathological diagnosis in Japan. Clin Exp Nephrol 12:277-291

32. Cabral DA, Canter DL, Muscal E, Nanda K, Wahezi DM, Spalding SJ, Twilt M, Benseler SM, Campillo S, Charuvanij S, Dancey P, Eberhard BA, Elder ME, Hersh A, Higgins GC, Huber AM, Khubchandani R, Kim S, Klein-Gitelman M, Kostik MM, Lawson EF, Lee T, Lubieniecka JM, McCurdy D, Moorthy LN, Morishita KA, Nielsen SM, O'Neil KM, Reiff A, Ristic G, Robinson AB, Sarmiento A, Shenoi S, Toth MB, Van Mater HA, Wagner-Weiner L, Weiss JE, White AJ, Yeung RS; ARChiVe Investigators Network within the PedVas Initiative (2016) Comparing presenting clinical features in 48 children with microscopic polyangiitis to 183 children who have granulomatosis with polyangiitis (Wegener's): an ARChiVe cohort study. Arthritis Rheumatol 68(10):2514-2526

33. Rottem M, Fauci AS, Hallahan CW, Kerr GS, Lebovics R, Leavitt RY, Hoffman GS (1993) Wegener granulomatosis in children and adolescents: clinical presentation and outcome. J Pediatr 122(1): 26-31

34. Langford C, Sneller M, Hallahan C, Hoffman G, Kammerer W, Talar-Williams C, Fauci AS, Lebovics RS (2008) Clinical features and therapeutic management of subglottic stenosis in patients with Wegener's granulomatosis. Lupus 17(9):832-836

35. Siomou E, Tramma D, Bowen C, Milford DV (2012) ANCAassociated glomerulonephritis/systemic vasculitis in childhood: clinical features-outcome. Pediatr Nephrol 27:1911-1920

36. Chipczyńska B, Grałek M, Hautz W, Zegadło-Mylik M, KocyłaKarczmarewicz B, Kanigowska K, Seroczyńska M, Kepa B, Klimczak-Slaczka D (2009) Orbital tumor as an initial manifestation of Wegener's granulomatosis in children: a series of four cases. Med Sci Monit 15(8):CS135-138

37. Jennette JC (2003) Rapidly progressive crescentic glomerulonephritis. Kidney Int 63(3):1164-1177

38. Hattori M, Kurayama H, Koitabashi Y (2001) Antineutrophil cytoplasmic autoantibody-associated glomerulonephritis in children. J Am Soc Nephrol 12:1493-500

39. Gendelman S, Zeft A, Spalding SJ (2013) Childhood-onset eosinophilic granulomatosis with polyangiitis (formerly Churg-Strauss Syndrome): A contemporary single-center cohort. J Rheumatol 40:929-935

40. Hauer HA, Bajema IM, Van Houwelingen HC, Ferrario F, Noël LH, Waldherr R, Noël LH, Waldherr R, Jayne D, Rasmussen N, Bruijn JA, Hagen, EC Clinical nephrology-epidemiology-clinical trials (2002) Determinants of outcome in ANCA-associated glomerulonephritis: A prospective clinico-histopathological analysis of 96 patients. Kidney Int 62:1732-1742

41. Neumann I, Kain R, Regele H, Soleiman A, Kandutsch S, Meisl FT (2005) Histological and clinical predictors of early and late renal outcome in ANCA-associated vasculitis. Nephrol Dial Transplant 20(1):96-104

42. Berden AE, Ferrario F, Hagen EC, Jayne DR, Jennette JC, Joh K, Neumann I, Noël LH, Pusey CD, Waldherr R, Bruijn JA, Bajema 
IM (2010) Histopathologic classification of ANCA-associated glomerulonephritis. J Am Soc Nephrol 21(10):1628-1636

43. Jayne D, Rasmussen N, Andrassy K, Bacon P, Tervaert JWC, Dadoniené J, Ekstrand A, Gaskin G, Gregorini G, de Groot K, Gross W, Hagen EC, Mirapeix E, Pettersson E, Siegert C, Sinico A, Tesar V, Westman K, Pusey C, European Vasculitis Study Group (2003) A randomized trial of maintenance therapy for vasculitis associated with antineutrophil cytoplasmic autoantibodies. N Eng1 J Med 349:36-44

44. Jayne DRW, Gaskin G, Rasmussen N, Abramowicz D, Ferrario F, Guillevin L, Mirapeix E, Savage CO, Sinico RA, Stegeman CA, Westman KW, van der Woude FJ, de Lind van Wijngaarden RA, Pusey CD, European Vasculitis Study Group (2007) Randomized trial of plasma exchange or high-dosage methylprednisolone as adjunctive therapy for severe renal vasculitis. J Am Soc Nephrol 18:2180-2188

45. Noone DG, Twilt M, Hayes WN, Thorner PS, Benseler S, Laxer RM, Parekh RS, Hebert D (2014) The new histopathologic classification of ANCA-associated GN and its association with renal outcomes in childhood. Clin J Am Soc Nephrol 9(10):1684-1691

46. Whiting-O'Keefe QE, Stone JH, Hellmann DB (1999) Validity of a vasculitis activity index for systemic necrotizing vasculitis. Arthritis Rheum 42(11):2365-2371

47. Luqmani RA, Bacon PA, Moots RJ, Janssen BA, Pall A, Emery P, Savage C, Adu D (1994) Birmingham Vasculitis Activity Score (BVAS) in systemic necrotizing vasculitis. QJM 87(11):671-678

48. Dolezalova P, Price-Kuehne FE, Özen S, Benseler SM, Cabral DA, Anton J, Brunner J, Cimaz R, O’Neil KM, Wallace CA, Wilkinson N, Eleftheriou D, Demirkaya E, Böhm M, Krol P, Luqmani RA, Brogan PA (2013) Disease activity assessment in childhood vasculitis: development and preliminary validation of the Paediatric Vasculitis Activity Score (PVAS). Ann Rheum Dis 72(10):1628-1633

49. Falk RJ, Jennette JC (1988) Anti-neutrophil cytoplasmic autoantibodies with specificity for myeloperoxidas in patients with systemic vasculitis and idiopathic necrotizing and crescentic glomerulonephritis. New Engl J Med 318:1651-1657

50. Wulffraat NM, Vastert B (2013) Time to share. Pediatr Rheumatol Online J 11(1):5

51. Morishita K, Guzman J, Chira P, Muscal E, Zeft A, Klein-Gitelman M, Uribe AG, Abramson L, Benseler SM, Eberhard A, Ede K, Hashkes PJ, Hersh AO, Higgins G, Imundo LF, Jung L, Kim S, Kingsbury DJ, Lawson EF, Lee T, Li SC, Lovell DJ, Mason T, McCurdy D, O’Neil KM, Punaro M, Ramsey SE, Reiff A, Rosenkranz M, Schikler KN, Scuccimarri R, Singer NG, Stevens AM, van Mater H, Wahezi DM, White AJ, Cabral DA, ARChiVe Investigators Network (2012) Do adult disease severity subclassifications predict use of cyclophosphamide in children with ANCAassociated vasculitis? An analysis of ARChiVe study treatment decisions. J Rheumatol 39(10):2012-2020

52. Bosch X, Guilabert A, Espinosa V, Mirapeix E (2007) Treatment of antineutrophil cytoplasmic antibody-associated vasculitis. J Am Med Assoc 298(6):655-669

53. Walsh M, Catapano F, Szpirt W, Bruchfeld A, Guillevin L, Haubitz M, Merkel PA, Peh CA, Pusey C, Jayne D (2011) Plasma exchange for renal vasculitis and idiopathic rapidly progressive glomerulonephritis: a meta-analysis. Am J Kidney Dis 57(4):566-574

54. Hoffman GS, Kerr GS, Leavitt RY, Hallahan CW, Lebovics RS, Travis WD, Rottem M, Fauci AS (2015) Wegener granulomatosis: An analysis of 158 patients. Ann Intern Med 116(6):488-498

55. de Groot K, Adu D, Savage CO (2001) The value of pulse cyclophosphamide in ANCA-associated vasculitis: meta-analysis and critical review. Nephrol Dial Transplant 16(10):2018-2027

56. De Groot K, Harper L, Jayne DRW, Suarez LFF, Gregorini G, Gross WL, Luqmani R, Pusey CD, Rasmussen N, Sinico RA, Tesar V, Vanhille P, Westman K, Savage CO, EUVAS (European
Vasculitis Study Group) (2009) Pulse versus daily oral cyclophosphamide for induction of remission in antineutrophil cytoplasmic antibody-associated vasculitis: A randomized trial. Ann Intern Med 150:670-680

57. Wegener T, Trial GE (2005) Etanercept plus standard therapy for Wegener's granulomatosis. N Engl J Med 352(4):351-361

58. The WGET Research Group (2002) Design of the Wegener's Granulomatosis Etanercept Trial (WGET). Control Clin Trials 23: 450-468

59. Booth A, Harper L, Hammad T, Bacon P, Griffith M, Levy J, Savage C, Pusey C, Jayne D (2004) Prospective study of TNFalpha blockade with infliximab in anti-neutrophil cytoplasmic antibody-associated systemic vasculitis. J Am Soc Nephrol 15(3): $717-721$

60. Laurino S, Chaudhry A, Booth A, Conte G, Jayne D (2010) Prospective study of TNFalpha blockade with adalimumab in ANCA-associated systemic vasculitis with renal involvement. Nephrol Dial Transplant 25(10):3307-3314

61. Jones R, Harper L, Ballarin J, Blockmans D, Brogan P, Bruchfeld A, Cid M, Dahlsveen K, Dezoysa J, Lanyon P, Peh CA, Tesar V, Vaglio A, Walsh M, Walsh D, Walters G, Jayne D (2013) A randomized trial of mycophenolate mofetil versus cyclophosphamide for remission induction of ANCA-associated vasculitis: "MYCYC". On behalf of the European Vasculitis Study Group. Presse Med 42:678-679

62. Walsh M, Casian A, Flossmann O, Westman K, Höglund P, Pusey C, Jayne DR, European Vasculitis Study Group (EUVAS) (2013) Long-term follow-up of patients with severe ANCA-associated vasculitis comparing plasma exchange to intravenous methylprednisolone treatment is unclear. Kidney Int 84:397-402

63. Mukhtyar C, Guillevin L, Cid MC, Dasgupta B, de Groot K, Gross W, Hauser T, Hellmich B, Jayne D, Kallenberg CG, Merkel PA, Raspe H, Salvarani C, Scott DG, Stegeman C, Watts R, Westman K, Witter J, Yazici H, Luqmani R, European Vasculitis Study Group (2009) EULAR recommendations for the management of primary small and medium vessel vasculitis. Ann Rheum Dis 68:310-317

64. Walsh M, Merkel PA, Peh CA, Szpirt W, Guillevin L, Pusey CD, De Zoysa J, Ives N, Clark WF, Quillen K, Winters JL, Wheatley K, Jayne D, PEXIVAS Investigators (2013) Plasma exchange and glucocorticoid dosing in the treatment of anti-neutrophil cytoplasm antibody associated vasculitis (PEXIVAS): protocol for a randomized controlled trial. Trials 14:73

65. Hiemstra TF, Walsh M, Mahr A, Savage CO, de Groot K, Harper L, Hauser T, Neumann I, Tesar V, Wissing KM, Pagnoux C, Schmitt W, Jayne DR, European Vasculitis Study Group (EUVAS) (2011) Mycophenolate mofetil vs azathioprine for remission maintenance in antineutrophil cytoplasmic antibody-associated vasculitis. JAMA 304(21):2381-2388

66. Sanders JSF, Stassen PM, Kallenberg CGM, Stegeman CA (2007) Azathioprine as compared to cyclophosphamide maintenance therapy for PR3-ANCA-associated vasculitis is associated with increased longterm relapse risk. Clin Exp Rheumatol 46:1087-1091

67. Metzler C, Miehle N, Manger K, Iking-Konert C, de Groot K, Hellmich B, Gross WL, Reinhold-Keller E, German Network of Rheumatic Diseases (2007) Elevated relapse rate under oral methotrexate versus leflunomide for maintenance of remission in Wegener's granulomatosis. Rheumatology 46(7):1087-1091

68. Jones RB, Tervaert JWC, Hauser T, Luqmani R, Morgan MD, Peh CA, Savage CO, Segelmark M, Tesar V, van Paassen P, Walsh D, Walsh M, Westman K, Jayne DR, European Vasculitis Study Group (2010) Rituximab versus cyclophosphamide in ANCA-associated renal vasculitis. N Engl J Med 363(3):211-220

69. Stone J, Merkel P, Spiera R, Seo P, Langford C, Hoffman G, Kallenberg CG, St Clair EW, Turkiewicz A, Tchao NK, Webber L, Ding L, Sejismundo LP, Mieras K, Weitzenkamp D, Ikle D, Seyfert-Margolis V, Mueller M, Brunetta P, Allen NB, Fervenza 
FC, Geetha D, Keogh KA, Kissin EY, Monach PA, Peikert T, Stegeman C, Ytterberg SR, Specks U, RAVE-ITN Research Group (2010) Rituximab versus cyclophosphamide for ANCAassociated vasculitis. N Engl J Med 363(3):221-232

70. Guillevin L, Pagnoux C, Karras A, Khouatra C, Aumaitre O, Cohen P, Maurier F, Decaux O, Ninet J, Gobert P, Quémeneur T, Blanchard-Delaunay C, Godmer P, Puéchal X, Carron PL, Hatron PY, Limal N, Hamidou M, Ducret M, Daugas E, Papo T, Bonnotte B, Mahr A, Ravaud P, Mouthon L, French Vasculitis Study Group (2014) Rituximab versus azathioprine for maintainance in ANCAassociated vasculitis. N Engl J Med 371:1771-1780

71. Jones RB, Furuta S, Cohen Tervaert JW, Hauser T, Luqmani R, Morgan MD, Peh CA, Savage CO, Segelmark M, Tesar V, van Paassen P, Walsh M, Westman K0, Jayne DR; European Vasculitis Society (EUVAS) (2015) Rituximab versus cyclophosphamide in ANCA-associated renal vasculitis: 2-year results of a randomised trial. Ann Rheum Dis 74:1178-82.

72. Specks U, Merkel PA, Seo P, Spiera R, Langford CA, Hoffman GS, Kallenberg CG, St Clair EW, Fessler BJ, Ding L, Viviano L, Tchao NK, Phippard DJ, Asare AL, Lim N, Ikle D, Jepson B, Brunetta P, Allen NB, Fervenza FC, Geetha D, Keogh K, Kissin EY, Monach PA, Peikert T, Stegeman C, Ytterberg SR, Mueller M, Sejismundo LP, Mieras K, Stone JH, RAVE-ITN Research Group (2013) Efficacy of remission-induction regimens for ANCA-associated vasculitis. N Engl J Med 369:417-427

73. Smith RM, Jones RB, Guerry M-J, Laurino S, Catapano F, Chaudhry A, Smith KG, Jayne DR (2012) Rituximab for remission maintenance in relapsing antineutrophil cytoplasmic antibody-associated vasculitis. Arthritis Rheum 64(11):37603769

74. de Menthon M, Cohen P, Pagnoux C, Buchler M, Sibilia J, Detree F, Gayraud M, Khellaf M, Penalba C, Legallicier B, Mouthon L, Guillevin L (2011) Infliximab or rituximab for refractory Wegener's granulomatosis: long-term follow up. A prospective randomised multicentre study on 17 patients. Clin Exp Rheumatol 29[1 Suppl 64]:S63-71

75. Eleftheriou D, Melo M, Marks SD, Tullus K, Sills J, Cleary G, Dolezalova P, Ozen S, Pilkington C, Woo P, Klein N, Dillon MJ,
Brogan PA (2009) Biologic therapy in primary systemic vasculitis of the young. Rheumatology 48:978-986

76. Guerry MJCJ, Brogan P, Bruce IN, D’Cruz DP, Harper L, Luqmani R, Pusey CD, Salama AD, Scott DG, Savage CO, Watts RA, Jayne DR (2012) Recommendations for the use of rituximab in antineutrophil cytoplasm antibody-associated vasculitis. Rheumatology 51:634-643

77. Mcgeoch L, Twilt M, Famorca L, Bakowsky V, Barra L, Benseler S, Cabral DA, Carette S, Cox GP, Dhindsa N, Dipchand C, FifiMah A, Goulet M, Khalidi N, Khraishi MM, Liang P, Milman N, Pineau CA, Reich H, Samadi N, Shojania K, Taylor-Gjevre R, Towheed TE, Trudeau J, Walsh M, Yacyshyn E, Pagnoux C, Canadian Vasculitis research network (CanVasc) (2015) CanVasc recommendations for the management of antineutrophil cytoplasm antibody (ANCA)-associated vasculitides - executive summary. Can J Kidney Heal Dis 2(43):2-6

78. Jayne DR, Chapel H, Adu D, Misbah S, O'Donoghue D, Scott D, Lockwood CM (2000) Intravenous immunoglobulin for ANCAassociated systemic vasculitis with persistent disease activity. QJM 93(7):433-439

79. Genovese MC, Kaine JL, Lowenstein MB, Del GJ, Baldassare A, Schechtman J, Fudman E, Kohen M, Gujrathi S, Trapp RG, Sweiss NJ, Spaniolo G, Dummer W, ACTION Study Group (2008) Ocrelizumab, a humanized anti-CD20 monoclonal antibody, in the treatment of patients with rheumatoid arthritis: A phase I/II randomized, blinded, placebo-controlled, dose-ranging study. Arthritis Rheum 58(9):2652-2661

80. Nachman PH, Segelmark M, Westman K, Hogan SL, Satterly KK, Jennette JC, Falk R (1999) Recurrent ANCA-associated small vessel vasculitis after transplantation: A pooled analysis. Kidney Int $56: 1544-1550$

81. Geetha D, Alfonso E, True K, Valentina Irazabal M, Specks U, Seo P, Nachman P, Fervenza FC (2011) Renal transplantation in antineutrophil cytoplasmic antibody-associated vasculitis: a multicentre experience. Transplantation 91(12):1370-1375

82. Elmedhem A, Adu D, Savage COS (2003) Relapse rate and outcome of ANCA-associated small vessel vasculitis after transplantation. Nephrol Dial Transplant 18:1001-1004 